Gut, 1973, 14, 642-648

\title{
The diagnosis of iron deficiency in patients with Crohn's disease
}

\author{
J. A. CHILD, B. BROzOVIĆ, N. H. DYER, D. L. MOLlin, AND A. M. DAWSON
}

From St Bartholomew's Hospital, London, and Queen Elizabeth Hospital, Birmingham

SUMMARY Red cell indices were determined and bone marrow was examined in a selected group of 21 patients with Crohn's disease who had a routine peripheral blood picture suggestive of iron deficiency. Only nine ( $43 \%$ ) of these patients had no stainable iron stores in the marrow fragments and could be considered as being definitely iron deficient. All indirect measurements in the diagnosis of iron deficiency, except the total iron-binding capacity (TIBC), appeared likely to result in overdiagnosis. Iron-deficient erythropoiesis, without true deficiency, may be due to the inflammatory disease process and this study indicates that the examination of bone marrow aspirate is necessary for the certain diagnosis of iron deficiency in Crohn's disease.

Anaemia is a well known complication of Crohn's disease and deficiencies of iron, folate, and vitamin $B_{12}$ have been variously implicated as underlying causes, although the inflammatory disease process itself may also affect erythropoiesis (Dyer, Child, Mollin, and Dawson, 1972a).

The early reports that a hypochromic anaemia was to be found in approximately $50 \%$ of patients with Crohn's disease (Plum and Warburg, 1939; Clark and Dixon, 1939) led to the general view that iron deficiency was the common cause of anaemia, and it has been stated recently that 'the majority of patients have an iron deficiency anaemia' (Fielding, 1972). As blood film appearances and red cell indices suggestive of iron deficiency may occur in inflammatory disease states when there is no true iron deficiency (Bainton and Finch, 1964; Cartwright, 1966; Cartwright and Lee, 1971) and the values for serum iron and iron-binding capacity may be inconclusive (Beutler, Robson, and Buttenweiser, 1958; Cartwright, 1966; Scott and Pritchard, 1967; Nixon and Olson, 1969), the ultimate criterion for the diagnosis of iron deficiency should be the absence of bone marrow iron stores. Hoffbrand, Stewart, Booth, and Mollin (1968), in a study of folate deficiency in Crohn's disease, recorded that nine $(39 \%)$ of 22 patients had no iron in the bone marrow. Dyer et al (1972a) investigated 63 patients with Crohn's disease and found bone marrow iron stores to be absent in the same proportion of patients

Received for publication 31 May 1973.
$(39 \%)$ but they also noted features suggestive of iron deficiency in the blood films of $50 \%$ of patients. In order to examine further the significance of an 'irondeficient' blood picture in Crohn's disease and the relation to iron status based on marrow examination, the present investigation was carried out.

\section{Materials and Methods}

Twenty-one patients with Crohn's disease had suggestive evidence of iron deficiency in the routine blood picture, ie, hypochromia, with or without microcytosis in the blood film and/or red cell indices which indicated the possibility of iron deficiency. All were inpatients, having been admitted because of symptoms referable to Crohn's disease. The diagnosis of Crohn's disease had been or was subsequently established by histology in all but seven patients, in whom the diagnosis was based on typical clinical and radiological features. There were nine men and 12 women. Eight patients had previously undergone resection of diseased bowel. Five patients had extensive disease involving small bowel and colon; nine patients had disease involving terminal ileum and caecum; two patients had terminal ileal and proximal colonic involvement (ileo-colic); and five had predominantly colonic involvement. The activity of the disease was arbitrarily graded, by a scoring system based on certain clinical and laboratory findings (Dyer, 1970), into seven grades. Grades 0 -III were regarded as mild to moderate and grades IV-VI were designated as 'active'. Of the 21 patients, 
eight (38\%) had 'active' disease. Four patients were on small maintenance doses of prednisone/prednisolone at the time of the initial investigations. None of the patients had received a total dose infusion of iron in the past. Red cell indices were determined and bone marrow aspiration was carried out in all patients. Thirteen of the 21 patients were investigated biochemically in more detail than the rest. Twelve patients were re-assessed haematologically following an interval of three months' treatment. None of these 12 patients underwent surgery or was transfused during this period, and their treatment, in addition to simple symptomatic treatment, which was unlikely to affect haemopoiesis, took the form of iron, steroids (prednisone/prednisolone) or a combination of both. Iron therapy initially took the form of a total dose infusion to ensure correct dosage and to avoid gastrointestinal upset. The dose of steroids varied according to response but those patients who were started on steroids for the first time were given maximum doses (40-60 mg/day) initially and reducing doses subsequently.

Haemoglobin level ( $\mathrm{Hb})$ was determined by cyanmethaemoglobin photoelectric colorimetry and the packed cell volume (PCV) was measured by a micromethod (Dacie and Lewis, 1968). The accepted normal ranges for these methods are: $\mathrm{Hb}, 13 \cdot 5-18.0$ $\mathrm{g} / 100 \mathrm{ml}$ (men); $11.5-16.5 \mathrm{~g} / 100 \mathrm{ml}$ (women); PCV, 40-54\% (men); $35-47 \%$ (women). Mean cell volume (MCV) was obtained using the Waterfield spherocytometer (Child, King, Newman, and Waterfield, $1966,1967)$. The normal range is $80-97 \mathrm{fl}$. Mean corpuscular haemoglobin (MCH) and mean corpus- cular haemoglobin concentration (MCHC) were derived by calculation from the measured indices. The accepted normal ranges for these methods are $27-32 \mathrm{pg}$ and $30-35 \%$, respectively (Dacie and Lewis, 1968). It should be noted that the MCHC was derived from the haemoglobin level and PCV not from electronically produced indices.

Films of bone marrow aspirates were stained with May-Grunwald-Giemsa and in addition, for iron, with potassium ferrocyanide. The evaluation of iron stores was based on the examination of three films, in which several marrow fragments could be seen. The stainable bone marrow iron stores were graded as absent $(0)$, diminished $(+)$, normal $(++)$, or increased $(+++)$ by the criteria of Beutler et al (1958).

Serum iron concentration was measured by an automated micromethod (Garry and Owen, 1967) using an AutoAnalyzer (Technicon); normal values range from 65 to $160 \mu \mathrm{g} / 100 \mathrm{ml}$. Unsaturated ironbinding capacity was measured by a semi-automated micromethod with radioactive iron (Brozović and Copestake, 1969). From these two measurements the total iron-binding capacity (TIBC) and the transferrin saturation were calculated; the normal ranges are 290 to $410 \mu \mathrm{g} / 100 \mathrm{ml}$ and 20 to $50 \%$, respectively. The uptake of iron in vitro by reticulocytes was determined as described by Brozovic (1970). Iron uptake by reticulocytes is normally less than $0.2 \mu \mathrm{g}$ $\mathrm{Fe} / \mathrm{ml}$ reticulocytes. Increased iron uptake indicates iron deficiency, and values above $0.5 \mu \mathrm{g} \mathrm{Fe} / \mathrm{ml}$ reticulocytes have been consistently found in irondeficiency anaemia (Brozović, 1970).

\begin{tabular}{|c|c|c|c|c|c|c|}
\hline Patient & Age (yr) & Duration of Symptoms (yr) & Site of Disease & Grade & Haemoglobin $(\mathrm{g} / 100 \mathrm{ml})$ & Bone Marrow Iron Stores \\
\hline M.W. 우 & 38 & 25 & Ileo-caecal & $\mathbf{I}$ & $11 \cdot 7$ & 0 \\
\hline S.H. ${ }^{\top}$ & 36 & 12 & Colic & I & $6 \cdot 7$ & $\mathbf{0}$ \\
\hline E.C. 9 & 44 & 10 & Ileo-caecal & I & $12 \cdot 6$ & $0^{1}$ \\
\hline J.K. $\stackrel{+}{+}$ & 34 & 11 & Ileo-caecal & II & $11 \cdot 2$ & $\mathbf{0}^{1}$ \\
\hline E.L. $\stackrel{+}{+}$ & 46 & 15 & Colic & II & 8.8 & 0 \\
\hline J.C.(a) 우 & 33 & 10 & Ileo-caecal & II & $10 \cdot 2$ & $\mathbf{0}$ \\
\hline P.B. o & 15 & 1 & Ileo-caecal & II & 11.9 & + \\
\hline D.M. ơ & 18 & $<1$ & Extensive & II & $12 \cdot 2$ & $+t+$ \\
\hline R.M. đ* & 21 & 4 & Ileo-caecal & III & $11 \cdot 6$ & 0 \\
\hline M.H. ठే & 16 & 4 & Ileo-caecal & III & $8 \cdot 8$ & 0 \\
\hline S.S. $\sigma^{*}$ & 31 & 2 & Colic & III & $10 \cdot 2$ & + \\
\hline I.H. 우 & 37 & $\overline{1}$ & Ileo-caecal & III & $12 \cdot 2$ & + \\
\hline J.C.(b) 9 & 26 & 7 & Ileo-caecal & III & $11 \cdot 0$ & + \\
\hline L.A. $\&$ & 29 & 12 & Ileo-caecal & IV & $6 \cdot 1$ & 0 \\
\hline H.R. ฮే & 42 & 2 & Colic & IV & $11 \cdot 2$ & + \\
\hline C.W. $\$$ & 15 & 2 & Extensive & IV & $8 \cdot 1$ & +2 \\
\hline C.J. $0^{+}$ & 24 & 2 & Colic & IV & $10 \cdot 3$ & + \\
\hline D.C. $q$ & 22 & 3 & Ileo-caecal & IV & $9 \cdot 7$ & + \\
\hline A.M. 우 & 25 & $<1$ & Extensive & IV & $11 \cdot 8$ & + \\
\hline R.P. $\sigma^{\top}$ & 21 & 3 & Extensive & $\mathbf{V}$ & $10 \cdot 2$ & $+t$ \\
\hline $\mathbf{N}, \mathbf{W} .0$ & 33 & 1 & Extensive & $\mathbf{v}$ & $8 \cdot 5$ & $++t^{2}$ \\
\hline
\end{tabular}

'Table I Clinical details, haemoglobin levels, and bone marrow iron status of 21 patients with Crohn's disease

${ }^{1}$ Marrow also showed mild megaloblastic change

${ }^{2}$ Marrow also showed marked megaloblastic change 


\section{Results}

HAEMOGLOBIN LEVELS

The values are given in table $I$. All the men and all but four of the women were anaemic.

THE MEAN CORPUSCULAR HAEMOGLOBIN CONCENTRATION (FIG 1)

This ranged from 23.5 to $32.0 \%$. Twelve patients $(57 \%)$ had low values $(<30 \%)$, and, of these, only seven had no iron stores. Two patients with no iron stores had values above $30 \%$.

\section{THE MEAN CORPUSCULAR HAEMOGLOBIN}

(FIG 1)

This ranged from 13.0 to $31.5 \mathrm{pg}$. Eighteen patients $(86 \%)$ had low values ( $<27 \mathrm{pg})$ and of these only nine had no iron stores.

THE MEAN CELL VOLUME (FIG 1)

This ranged from 55 to $109 \mathrm{fl}$. Thirteen patients $(62 \%)$
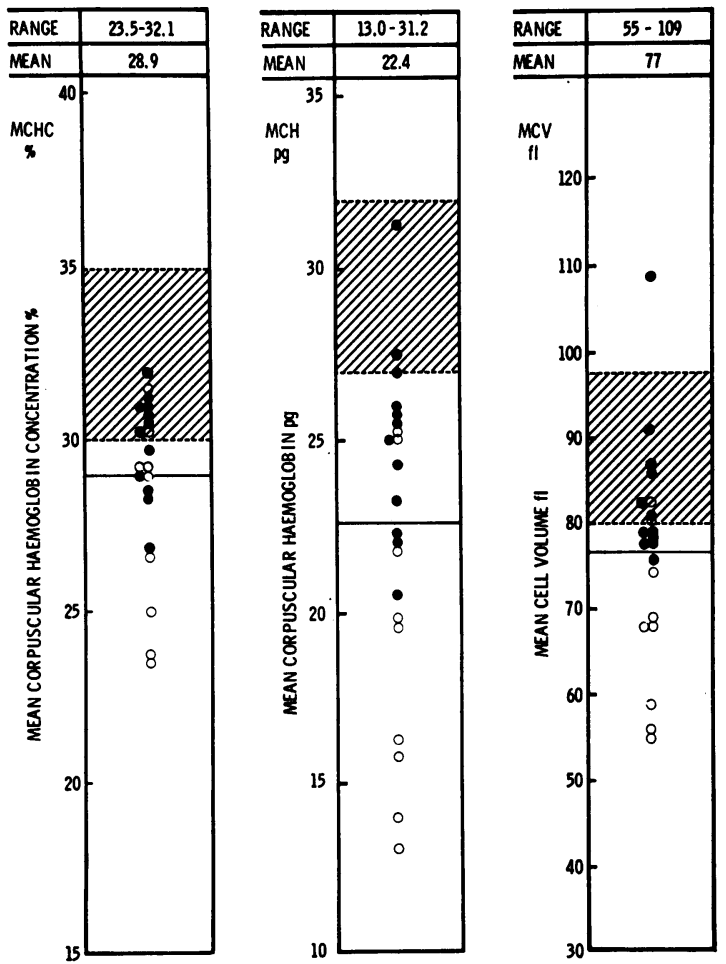

Fig 1 The distribution of values for $M C H C, M C H$, and $M C V$.

Open circles indicate patients with no iron stores. The shaded areas represent the normal ranges and solid horizontal lines, the means for the patients. had low values ( $<80 \mathrm{fl})$ and of these only seven had no iron stores. Two patients without iron stores had values above $80 \mathrm{fl}$.

SERUM IRON, TIBC, TRANSFERRIN SATURATION, AND IRON UPTAKE BY RETICULOCYTES

(13 PATIENTS) (FIG 2)

Serum iron concentration was reduced in all the patients regardless of the amount of stainable iron in the bone marrow. Total iron-binding capacity was increased in four patients, all of whom had no marrow iron stores. In most of the patients with stainable iron in the bone marrow, TIBC was below the lower limit of normal and in only two patients was it within the normal range. Transferrin saturation was low in all except one of these patients. Iron uptake by reticulocytes was increased in all but four patients, three of whom had reduced, one normal, and one increased, iron stores.
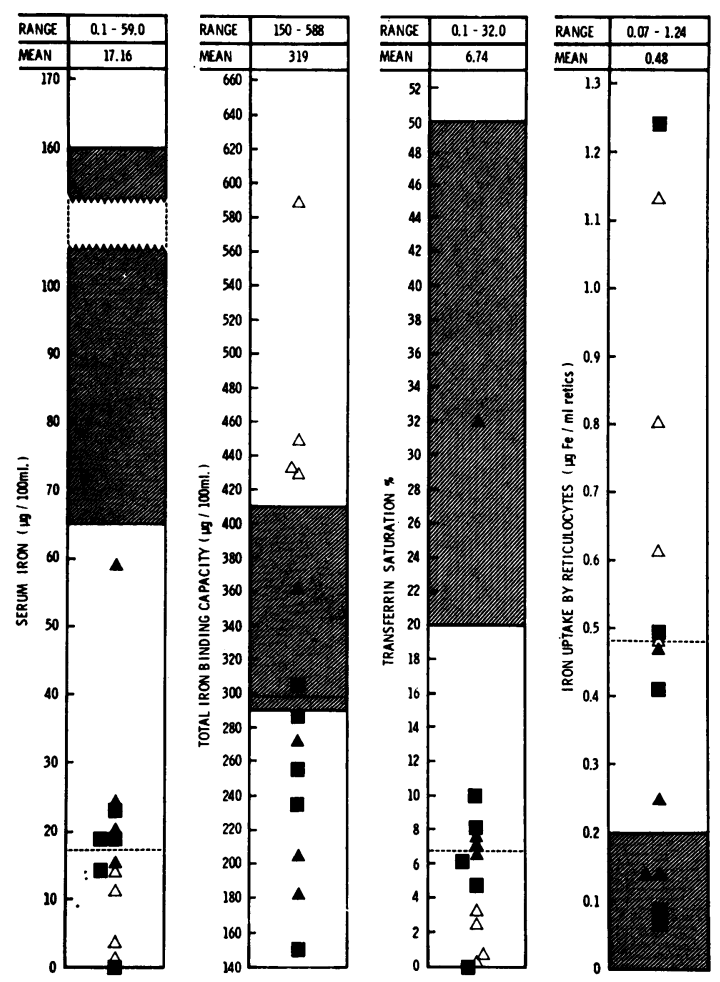

Fig 2 The distribution of values for serum iron, total iron-binding capacity, transferrin saturation, and iron uptake by reticulocytes $\Delta$ female

Open symbols indicate patients with no iron stores. The shaded areas represent normal ranges and interrupted horizontal lines, the means for the patients. 
OCCULT BLOOD IN STOOL

Routine tests did not suggest significant blood loss in any patient except one (C.J.) with rectal involvement by the inflammatory process.

BONE MARROW ASSESSMENT

Two patients (C.W. and N.W.) had marked megaloblastic change associated with folate deficiency. A further two patients (E.C. and J.K.) had mild megaloblastic change and no iron stores; they also were folate deficient.

Iron stores, as evaluated by the examination of the stainable iron in the marrow aspirate, were completely absent $(0)$ in nine patients, reduced $(+)$ in nine patients, normal $(++)$ in one patient, and increased $(t++)$ in two patients (table $I)$.

\section{THE PATIENTS WITH ABSENT IRON STORES}

\section{Women (7 patients)}

Three (M.W., J.K., and E.L.) had menorrhagia and subsequently underwent hysterectomy. Two of these patients had uterine fibroids.

Two others (L.A. and E.C.) were anorexic for long periods and could be regarded as having generally deficient diets with low iron intake. Both were menstruating, but apparently not excessively.

The remaining two (S.H. and J.C.(a)) were menstruating women who did not appear to have inadequate diets, excessive menstrual loss, or any other significant blood loss.

\section{Men (2 patients)}

One was pubertal (M.H., aged 16) and showed evidence of retarded development, the other (R.M., aged 21) had been ill for four years with severe Crohn's disease.

\section{RELATIONSHIP BETWEEN IRON STATUS} SHOWN BY BONE MARROW EXAMINATION AND OTHER PARAMETERS

\section{The red cell indices}

Whilst the lower values for $\mathrm{MCHC}, \mathrm{MCH}$, and $\mathrm{MCV}$ were found in those with no iron stores (fig 2) there was no significant correlation between the presence or absence of iron stores and values for these indices above or below the accepted lower limits of normal. (The Chi square test with Yates's correction was used.)

Serum iron, $T I B C$, transferrin saturation, and iron uptake by reticulocytes

Although all patients investigated had reduced serum iron concentrations and all, except one, greatly reduced transferrin saturations (fig 3) only the four patients with no iron stores in the marrow had values for TIBC above the normal range. In addition, in the latter patients, iron uptake by reticulocytes was appreciably increased. Therefore, in these four patients there was a perfect agreement between all the parameters measured, which unequivocally indicated iron deficiency. The rise in the haemoglobin levels after treatment with iron was further evidence that these patients were lacking iron. The remaining patients with reduced $(t)$, normal $(+t)$, or increased $(+++)$ stainable iron in the bone marrow had reduced serum iron concentrations, reduced or
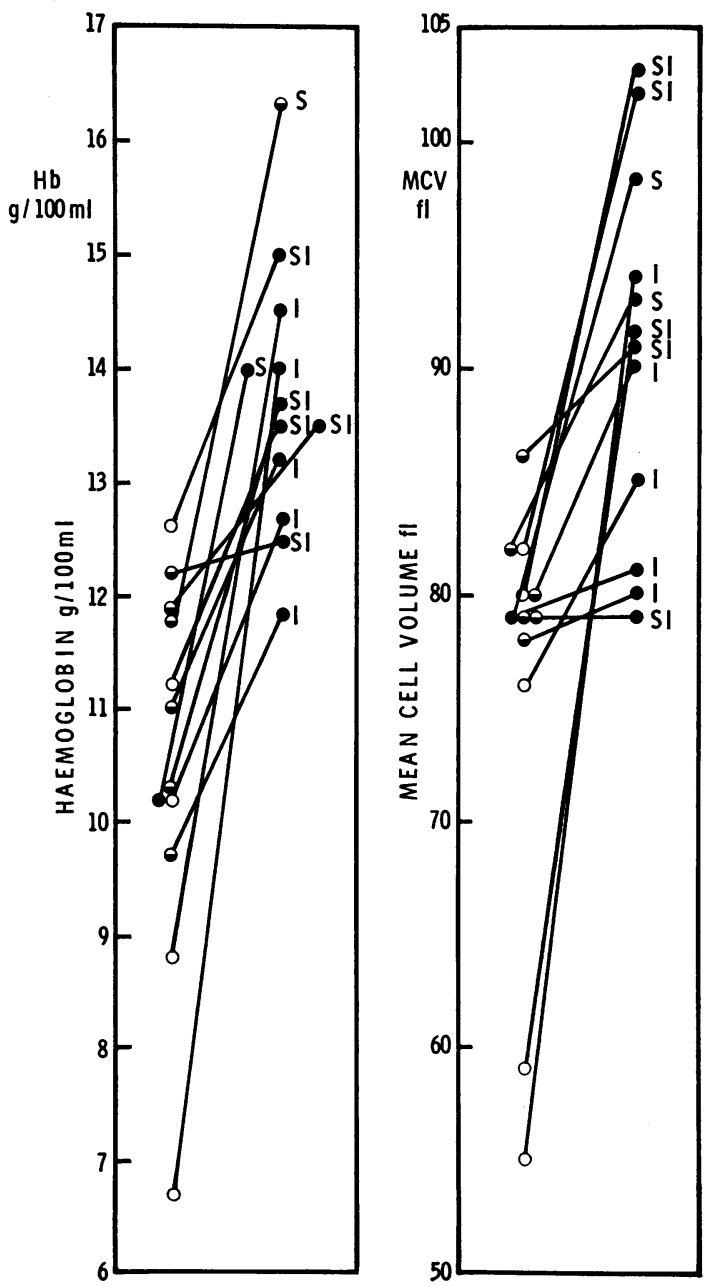

Fig 3 The comparison between the values for haemoglobin level and for MCV on admission and three months after starting treatment ${ }^{1}$ in 12 patients.

'I, iron; S, steroids; SI, steroids and iron. 
normal TIBC, and decreased transferrin saturations (with one exception); the iron uptake by reticulocytes was normal or modestly increased except in one patient (C.J.) These features were more suggestive of 'the anaemia of chronic disease' than iron-deficiency anaemia.

\section{THE HAEMATOLOGICAL RESPONSE TO} TREATMENT

The changes in haemoglobin levels and MCV in 23 patients when re-assessed following an interval of three months are shown, with the bone marrow iron status, in fig 3 and table II. The principal forms of treatment of possible haematological relevance are also indicated.

There were increases in haemoglobin level in all patients (significant increases in all except I.H.) and increases in MCV in all but one patient (P.B.). Iron repletion in the four patients with no iron stores produced marked changes in MCV. However, two (J.K. and E.C.) were also folate deficient and this was presumably the underlying cause of the macrocytosis, which was not a transient phenomenon following iron therapy but due to megaloblastic change. Two patients (A.M. and R.P.) showed a good response to steroids alone.

\section{Discussion}

The present study of patients with Crohn's disease suggests that whereas very low values for MCHC, $\mathrm{MCH}$, and MCV are usually associated with the absence of marrow iron stores, there are patients with subnormal values for these indices who have iron stores in the marrow. A peripheral blood film and red cell indices which suggest the possibility of iron deficiency may or may not indicate true iron deficiency (Bainton and Finch, 1964); it may equally be due to ineffective iron utilization-iron-deficient erythropoiesis without iron deficiency. This is said to be especially true in inflammatory disease states (Bainton and Finch, 1964; Cartwright and Lee, 1971). It is apparent that reliance on the peripheral blood picture alone will result in the overdiagnosis of iron deficiency in Crohn's disease.

Of the other indirect aids to diagnosis, the serum iron concentration was below normal and generally very low in all 13 patients investigated, though only four of this group had no iron stores. Both the present and a previous study (Dyer et al, 1972a) indicate that a low serum iron would not be reliable in the diagnosis of iron deficiency in Crohn's disease. Similarly, a low percentage transferrin saturation was found in all but one of these patients. It has been observed by several workers that serum iron concentrations are reduced, and sometimes markedly so, in patients with chronic inflammatory disease states when there is no true iron deficiency (Bainton and Finch, 1964; Nixon and Olson, 1969; Cartwright and Lee, 1971) and yet assumption of iron deficiency on this basis is still made (Eade, Cooke, and Williams, 1972). The increased TIBC was of more diagnostic value and was found in all those patients with no iron stores. The previous study, which included more patients, demonstrated that the absence of iron stores is not necessarily associated with an increased TIBC and a subnormal TIBC does not definitely exclude iron deficiency (Dyer et al, 1972a). The reticulocyte uptake of iron was increased in those patients with no iron stores but did not provide a sharp differentiation.

In this selected group of patients with peripheral blood pictures suggestive of iron deficiency, bone marrow iron stores were absent in only nine $(43 \%)$ 
of the 21 patients. A further nine had reduced iron stores (all of these had more than the 'trace' amounts sometimes encountered). For the purpose of this study, iron deficiency based on marrow iron stores was defined in 'all-or-none' terms. The significance of reduced stores is not clear, especially in patients with chronic inflammatory disease states, and further work is urgently required to clarify this. However, it is generally accepted that hypochromia in the blood film, red cell indices of iron deficiency, and marked reduction in serum iron and transferrin saturation do not usually occur until iron stores are exhausted (Beutler et al, 1958; Bothwell and Finch, 1962; Conrad and Crosby, 1962). Two patients had increased iron stores. This apparent contradiction of abundant iron and iron-deficient erythropoiesis is found typically in association with chronic inflammation and malignancy (Bainton and Finch, 1964; Cartwright, 1966).

It is worth noting that, in complete contrast, marrow iron stores may sometimes be absent with no associated peripheral blood abnormalities (Stevens, Coleman, and Finch, 1953; Beutler, 1959; Ellis, Jensen, and Westerman, 1964; Verloop, 1970; Child, Bowry, and Knowles, 1973).

Although the response to treatment should provide further evidence as to the cause of the 'irondeficient' blood picture, there are obvious difficulties in distinguishing the separate effects of the natural course of the disease, altered nutritional status, treatment of the inflammatory disease process itself, and treatment with haematinics. It seemed likely that those patients with no iron stores would only respond rapidly to the administration of iron and there was, indeed, a clear response in terms of increase in haemoglobin levels and MCV with repletion of the bone marrow iron stores. None of these patients had 'active' Crohn's disease (> grade III). The haematological response to iron therapy in patients with reduced iron stores was generally much less striking; in all except two cases steroids were also given in full doses. There is no good evidence that iron therapy alone will benefit such patients, although restoration of their reserves to normal may be desirable. Theoretically, the iron-deficient erythropoiesis which is not caused by 'true' iron deficiency should respond to treatment which reduces the activity of the inflammatory process, and the fact that two patients (A.M. and R.P.) with active disease showed an apparent reversion to normal erythropoiesis following treatment with steroids alone provides some tentative evidence to suggest that this may be so.

Of the nine patients with no iron stores, three women had pathological blood loss unrelated to Crohn's disease. Dietary inadequacies appeared to be a likely cause of iron deficiency in four other patients, though intestinal blood loss could not be definitely excluded. It appears that about a third of apparently healthy non-anaemic women of childbearing age have no or depleted bone marrow iron stores (de Leeuw, Lowenstein, and Yang-Shu Hsieh, 1966; Scott and Pritchard, 1967; Hallberg, Högdahl, Nilsson, and Rybo, 1968) and the incidence of iron deficiency in females with Crohn's disease is probably only slightly above that in the 'normal' population. Clearly, iron deficiency could result from blood loss from the intestinal lesions of Crohn's disease, although preliminary investigations of Dyer, James, and Meynell (1972b) suggest that the intestinal blood loss is often minimal. Dietary deficiency of iron may be of more importance in producing the iron-deficient state. This question requires further examination.

There may well be a more 'precarious' iron balance in many patients with Crohn's disease due to reduced dietary intake and, possibly, intermittent intestinal blood loss. However, true iron deficiency is probably less frequent than previously thought, and it is suggested that the examination of bone marrow is a useful and justifiable investigation in patients with this disease.

\section{References}

Bainton, D. F., and Finch, C. A. (1964). The diagnosis of iron deficiency anemia. Amer. J. Med., 37, 62-70.

Beutler, E. (1959). The red cell indices in the diagnosis of iron deficiency anemia. Ann. intern. Med., 50, 313-322.

Beutler, E., Robson, M. J., and Buttenweiser, E. A. (1958). A comparison of the plasma iron, iron binding capacity, sternal marrow iron and other methods in the clinical evaluation of iron stores. Ann. intern. Med., 48, 60-82.

Bothwell, T. H., and Finch, C. A. (1962). Iron Metabolism. Little, Brown, Boston.

Brozovic, B. (1970). Uptake of radioactive iron by reticulocytes in vitro: method of assay and its value as a test for iron deficiency. $\mathrm{PhD}$ Thesis, University of London.

Brozović, B., and Copestake, J. (1969). Semi-automated micromethod for estimating the unsaturated iron-binding capacity of serum using radioactive iron. J. clin. Path., 22, 605-608.

Cartwright, G. E. (1966). The anemia of chronic disorders. Semin. Haemat., 3, 351-375.

Cartwright, G. E., and Lee, G. R. (1971). The anaemia of chronic disorders. Brit. J. Haemat., 21, 147-152.

Child, J. A., Bowry, W. M. P., and Knowles, J. P. (1973). Iron deficiency in patients with chronic obstructive airways disease. Scand. J. Haemat., 10, 44-53.

Child, J. A., King, J., Newman, T. H., and Waterfield, R. L. (1966). A diffraction method for measuring the average size and shapes of red blood cells. Lancet, 2, 891-892.

Child, J. A., King, J., Newman, T. H., and Waterfield, R. L. (1967). A diffraction method for measuring the average volumes and shapes of red blood cells. Brit. J. Haemat., 13, 364-375.

Clark, R. L., Jr., and Dixon, C. F. (1939). Regional enteritis. Surgery, 5, $277-304$.

Conrad, M. E., and Crosby, W. H. (1962). The natural history of iron deficiency induced by phlebotomy. Blood, 20, 173-185.

Dacie, J. V., and Lewis, S. M. (1968). Practical Haematology, 4th ed. Churchill, London.

de Leeuw, N. K. M., Lowenstein, L., and Yang-Shu Hsieh (1966). Iron deficiency and hydremia in normal pregnancy. Medicine (Baltimore), 45, 291-315. 
Dyer, N. H. (1970). Studies on Crohn's disease. MD Thesis, University of Cambridge.

Dyer, N. H., Child, J. A., Mollin, D. L., and Dawson, A. M. (1972a). Anaemia in Crohn's Disease. Quart. J. Med., 41, 419-436.

Dyer, N. H., James, H., and Meynell, M. J. (1972b). Presented at the Midland Gastroenterological Society.

Eade, M. N., Cooke, W. T., and Williams, J. A. (1972). Clinical and hematologic features of Crohn's disease. Surg. Gynec. Obstet., 134, 643-646.

Ellis, L. D., Jensen, W. N., and Westerman, M. P. (1964). Marrow iron. An evaluation of depleted stores in a series of 1332 needle biopsies. Ann. intern. Med., 61, 44-49.

Fielding, J. F. (1972). Crohns disease of the small intestine and stomach. Brit. J. hosp. Med., 7, 767-774.

Garry, P. J., and Owen, G. M. (1967). Automated micro determination $(100 \mathrm{I} \eta)$ of serum iron and total iron binding capacity. In Automation in Analytical Chemistry: Technicon International Symposium, New York, p. 18. Technicon, New York. Mediad, White Plains, N.Y.

Hallberg, L., Högdahl, A. M., Nilsson, L., and Rybo, G. (1968). Varia- tion in iron loss in women. Occurrence, Causes, and Prevention of Nutritional Anaemias. Symposium of the Swedish Nutritional Foundation, edited by G. Blix, pp. 115-120. Almquist and Wiksell, Uppsala,

Hoffbrand, A. V., Stewart, J. S., Booth, C. C., and Mollin, D. L. (1968). Folate deficiency in Crohn's disease. Incidence, pathogenesis and treatment. Brit. med., J., 2, 71-75.

Nixon, R. K., and Olson, J. P. (1969). Diagnostic value of marrow haemosiderin patterns. Ann. intern. Med., 69, 1249-1254.

Plum, P., and Warburg, E. (1939). Hematological changes, especially megalocytic anemia, in regional ileitis. Acta med. scand., 102, 449-475.

Scott, D. E., and Pritchard, J. A. (1967). Iron deficiency in healthy young college women. J. Amer. med. Ass., 199, 897-900.

Stevens, A. R., Jr., Coleman, D. H., and Finch, C. A. (1953). Iron metabolism: clinical evaluation of iron stores. Ann. intern. Med., 38, 199-205.

Verloop, M. C. (1970). Iron depletion without anaemia : a controversial subject. Blood, 36, 657-671. 